San Jose State University

From the SelectedWorks of Lili Luo

March, 2019

\title{
Chinese College Students' Health Information Seeking Behavior: Implications for Academic Libraries
}

Yanxia Shi, Shanxi University

Lili Luo, San Jose State University 


\section{Chinese College Students' Health Information Seeking Behavior: Implications for Academic Libraries}

\section{Introduction}

In 2016, Zexi Wei, a 21-year old Chinese college student died after receiving experimental treatment for synovial sarcoma at the Second Hospital of the Beijing Armed Police Corps. He learned about this treatment from a promoted result on the Chinese search engine Baidu (the equivalent of Google in China), and ultimately discovered that the hospital had misled patients by providing fraudulent information about the treatment's success rate. Wei's death prompted Chinese regulators to investigate Baidu's advertising practices, and drew widespread attention from the public about the ill-regulated practices of online dissemination of health information. As academic librarians, this tragic incident has made us more vigilant about the ubiquity of questionable medical/health information in Chinese cyberspace, and caused us to wonder - how do Chinese college students seek health information? What are the criteria they use to evaluate the information? What can academic libraries do to help them become more information literate and health literate?

To answer these questions, we conducted focus group interviews with Chinese college students to examine their health information seeking behavior (HISB) and its implications for academic libraries. The ability to obtain, process, and understand basic health information and services needed to make appropriate health decisions is at the core of health literacy (U.S. Department of Health and Human Services, 2000; Ministry of Public Health of China, 2017). The Medical Library Association (MLA) further defines health information literacy as "the set of abilities needed to: recognize a health information need; identify likely information sources and use them to retrieve relevant information; assess the quality of the information and its applicability to a specific situation; and analyze, understand, and use the information to make good health decisions" (Kars, Baker \& Wilson, 2008). MLA encourages librarians in all types of libraries to play a major role in health literacy by helping consumers access and understand health information (Kars, Baker \& Wilson, 2008). Librarians are perfectly positioned to contribute to the health literacy movement as keepers of information, teachers and champions of information literacy, and liaisons to researchers and healthcare professionals who strive to improve health literacy (Barr-Walker, 2016). Particularly, in China, there is a lack of consumer-oriented health information sites that are authoritative and credible (e.g. the equivalent of MedlinePlus.gov), making it more critical for librarians to be active and proactive in bridging gaps in the citizenry's health literacy. We believe that an in-depth study investigating how students seek health information will yield valuable insights for librarians to develop resources, services and programs that could help college student become more critical consumers of health information, and ultimately lead to the enhancement of their health literacy.

\section{Literature Review}


Health literacy has been widely recognized as a major health care problem, and improved health literacy is often listed as an important objective in governments' health initiatives such as China's Healthy China 2030, or the United States' Healthy People 2020. Research has shown that low health literacy leads to poor health status and outcomes, such as lack of medical care knowledge, impaired comprehension of medical information, lack of knowledge about medical conditions, lack of understanding and use of preventive services, increased hospitalization and increased health care costs (Ickes \& Cottrell, 2010). Poor health literacy is considered a stronger predictor of a person's health than age, income, employment status, education level and race (Institute of Medicine, 2004).

College students is a population where research on their health literacy is much needed. Vogelpohl and Carpenter (2013) argued that college students are at a crucial stage of development and they are beginning to make lifelong health care decisions, and hence it is critical for them to develop proficient health literacy skills. Although college students do not fall under the category of the traditionally underserved who have difficulty in understanding health information, Ickes and Cottrell (2010) opined that it was problematic to merely focus on the traditionally underserved because "others who were not part of that target group, including educated individuals, missed their opportunity to obtain information and assistance as they made health care choices" (p. 492). Education was not necessarily an indicator of high health literacy skills (American Institute for Research, 2006), and thus, it is imperative to examine college students' health literacy and understand how they seek, evaluate and interpret health information in making health decisions in the increasingly complex information landscape.

Health information seeking behavior (HISB) is an essential area in health literacy research. However, the research on college students' HISB is limited. A comprehensive search in the literature only yielded ten relevant articles in the past ten years. When examining how college students seek health information, several studies looked at the types of information sought. Banas (2008), in her survey study of US college students' online health information literacy skills, found that most researched topics included a particular illness/condition, nutrition, exercise or weight control issues, mental health issues, a particular doctor/hospital, or a particular prescription drug. Obasola and Agunbiade (2016) surveyed undergraduates in Nigeria and found that students sought information on nutrition, fitness/exercise, HIV/AIDS, malaria, sore throat, mental health, menstrual pain and sexual/reproductive health. Asibey, Agyemang and Dankwah (2017) surveyed Ghanaian students about their internet use for health information seeking and learned that students mostly sought information related to specific illnesses and used online health information as a basis for lifestyle change. Sultan, Joshua and Misra (2017) conducted a survey among students in the Sultanate of Oman and learned that students primarily sought information pertinent to personal/family sickness or health messages in print or electronic media.

Regarding sources of health information, Percheski and Hargittai (2011) uncovered, in their survey of over 1,000 US college students, that family and friends were the most popular source of health information, while online sources, medical professionals and traditional media were also each used by $75 \%$ of the survey respondents. Meanwhile, females were more likely than males to use all sources of health information. Students with more highly educated parents were more likely to seek information from medical professionals and their family and friends. Students who lived with their parents were less likely to turn to medical professionals or the Web for health information. Asian/Asian American students were more likely to use their network of family and friends and traditional media than students of other ethnic and racial backgrounds. Non-native English speakers and people with more internet skills were 
more likely to seek health information online. The study by Sultan, Joshua and Misra (2017) slightly countered the findings from Percheski and Hargittai (2011), and identified internet as the most frequently consulted health information source. Following that are family members, non-doctor experts, and doctors/medics, all of which were used by more than three quarters of the respondents, and traditional media like television, newspapers and magazines were used by only $40 \%$ of the surveyed students. Islam et al (2017), in their study of Bangladesh students' HISB, noted that age, grade level, marital status and computer knowledge were associated with how extensively they used internet for health information seeking.

Studies that assessed college students' skills in searching and evaluating health information all agreed that students were not competent in health information seeking. Ivanitskaya, Boyle and Casey (2006) used the Research Readiness Self-Assessment instrument to measure university student's health information literacy level, and found that many students were not able to conduct advanced information searches, judge the trustworthiness of health related websites and articles, and differentiate between various information sources. This finding was echoed by ensuing research on this topic (Banas, 2008; Stellefson et al., 2011; Obasola \& Agunbiade, 2016). It was also worth noting that students tended to consider themselves as proficient in seeking health information though (Ivanitskaya, Boyl \& Casey, 2006; Stellefson et al., 2011). This discrepancy between their self-perception and their actual competencies, characterized as the Dunning-Kruger Effect, was also found in research about students' information literacy skills in general (Mahmood, 2016). Such findings further highlighted the importance and urgency of providing effective and efficient education to enhance students' health information literacy.

Very little research exists on the role of academic libraries in promoting health literacy on campus and assisting students in gaining health information competencies. Only one nation-wide survey examined how academic libraries were involved in health information outreach. Duhon and Jameson (2013) found that nearly $55 \%$ of the surveyed libraries did not engage in any health information outreach activities, but the majority of the respondents recognized that there is a potential role for academic librarians to provide health information to campus constituents, especially students. Their findings indicated that although providing consumer health information in the general academic library environment might be a relative rarity now, there seemed to be a captive audience and a logical need for it. Our study hopes to further contribute to this growing area of research through an in-depth investigation of Chinese college students' HISB and its implications for academic libraries.

\section{Research Procedures}

Focus group interviews were conducted among undergraduate students at a mid-size university in Shanxi Province, China. The university has a population of over 20,000 undergraduate students across 12 colleges.

A focus group generally involves 6 to 12 individuals discussing a particular topic under the direction of a moderator who promotes integration and ensures that the discussion remains on the topic of interest (Stewart, Shamdasani \& Rook, 2007). The basic purpose of the focused interview is to gather qualitative data from individuals about their experience or attitude regarding some particular concrete situation, which serves as the focus of the interview (Merton, 1987). Focus groups are commonly utilized for research that is either exploratory, clinical, and/or phenomenological (Calder, 1977). In this study, 
students' HISB was the "particular concrete situation" that required investigation. The study was relatively singular in focus and exploratory in nature. Thus, the focus group interview was determined to be a proper instrument for data collection.

The study population was defined as full-time undergraduate students enrolled in a four-year academic program at the university. Students were recruited through various social media outlets related to their campus life. A total of three focus groups were conducted and each focus group was about 90 minutes in length. As a standard component of a focus group study, food and beverage were provided. No monetary compensation was offered. Table 1 details the basic demographics of the participants in each focus group.

\begin{tabular}{|l|l|l|l|l|}
\hline & $\begin{array}{l}\text { \# of } \\
\text { Participants }\end{array}$ & $\begin{array}{l}\text { Participants' } \\
\text { Gender }\end{array}$ & $\begin{array}{l}\text { Participants' } \\
\text { Class Standing }\end{array}$ & Participants' Discipline \\
\hline $\begin{array}{l}\text { Focus Group } \\
1\end{array}$ & 9 & $\begin{array}{l}\text { Female (4) } \\
\text { Male (5) }\end{array}$ & $\begin{array}{l}\text { Junior (5) } \\
\text { Senior (4) }\end{array}$ & $\begin{array}{l}\text { Information Management (3) } \\
\text { Information System(3) } \\
\text { Computer Science (3) }\end{array}$ \\
\hline $\begin{array}{l}\text { Focus Group } \\
2\end{array}$ & 10 & $\begin{array}{l}\text { Female (4) } \\
\text { Male (6) }\end{array}$ & $\begin{array}{l}\text { Freshman (3) } \\
\text { Sophomore (4) } \\
\text { Junior (3) }\end{array}$ & $\begin{array}{l}\text { E-Commerce (3) } \\
\text { International Business (2) } \\
\text { Environmental Design (2) } \\
\text { Japanese Studies (1) } \\
\text { Optical Information Science and } \\
\text { Engineering (1) } \\
\text { Visual Art and Communications } \\
\text { (1) }\end{array}$ \\
\hline $\begin{array}{l}\text { Focus Group } \\
3\end{array}$ & 8 & Female (3) & $\begin{array}{l}\text { Freshman (3) } \\
\text { Sophomore (5) }\end{array}$ & $\begin{array}{l}\text { Mechanical Engineering (3) } \\
\text { Architectural Design (3) } \\
\text { Electrical Engineering (2) }\end{array}$ \\
\hline
\end{tabular}

Table 1. Demographics of focus group participants

The validity of focus group interviews is usually affected by the extent to which participants feel comfortable about openly communicating their ideas, views, or opinions. Stewart et al. (2007) summarized the variables that influence group dynamics into three broad categories: individual differences, interpersonal factors and environmental factors. In this study, we made conscious efforts to reduce the influences to a minimum. Regarding individual differences, the focus group participants, though all undergraduate students, spread across difference disciplines and grade levels, which helped alleviate the concerns of group conformity; meanwhile, the participants were well balanced in terms of gender and thus any pressure resulting from either a male dominant or female dominant group was avoided. From the interpersonal perspective, the participants were able to interact with each other in a friendly and respectful manner because they were relatively homogeneous in their identity as college students (e.g. entering college around 18 or 19 directly after graduating from high school, living in campus dorms, and required to take the same GE courses).The topic of interest was not a sensitive issue that could have provoked strong emotional responses. All participants were encouraged to contribute to the discussion, and the moderator would direct the conversation to allow the more vocal participants to fully express themselves without making the more reticent ones feel excluded. Environmental factors usually encompass the spatial arrangement of the interview. All of the focus group interviews took place in a secure, well-lit conference room in a campus building that participants were familiar with. Overall, 
we felt confident that the factors affecting focus group dynamics were under control, and the participants were able to communicate openly and comfortably throughout the interview.

The focus group interview guide was developed based on the research questions, focusing on four main areas of inquiry: motivations for students' HISB, information sources consulted, criterial for information evaluation, and perceptions of using academic libraries in seeking health information. All three focus groups were audio-recorded and transcribed. When coding the transcripts, inductive thematic coding was applied. Inductive coding followed a three-step process (Babbie, 2013): open coding for initial classification and labeling of codes, axial coding to identify the core concepts, and selective coding to determine the relationships between codes and uncover the central themes. Two coders coded the transcripts, and resolved their conflicts in the coding process to arrive at $100 \%$ agreement.

\section{Findings}

\subsection{Motivations for Seeking Health Information}

Students actively seek health information in four occasions primarily. First, when they experience injury or physical discomfort personally, they look for information on symptoms and treatment to help them decide what to do next; secondly, in their pursuit of healthy living style, they explore information pertinent to their particular needs; thirdly, when their friends encounter health concerns, they try to locate relevant information to help them out; and finally, they seek health information to gain knowledge on particular health topic. Table 2 below presents exemplar quotes representing each type of motivations for students' active HISB.

\begin{tabular}{|c|c|}
\hline Type of Motivation & Exemplar Quotes \\
\hline $\begin{array}{l}\text { Personal medical } \\
\text { condition }\end{array}$ & $\begin{array}{l}\text { "My finger got caught in a door, and I went online to find information on } \\
\text { how to treat it." } \\
\text { "My joints started hurting after long distance running and I was afraid that it } \\
\text { might be arthritis. So I looked up information on joint pain and what might } \\
\text { cause arthritis." }\end{array}$ \\
\hline $\begin{array}{l}\text { Pursuit of healthy } \\
\text { living }\end{array}$ & $\begin{array}{l}\text { "I regularly watch online videos about how to lose weight, such as exercises } \\
\text { targeting different parts of the body." } \\
\text { "I follow popular accounts about fitness on social media. I want to know } \\
\text { what kinds of diet would help muscle strengthening." }\end{array}$ \\
\hline $\begin{array}{l}\text { Friends' health } \\
\text { concerns }\end{array}$ & $\begin{array}{l}\text { "My friends was hurt badly in a relationship and became distraught, and she } \\
\text { even started doubting herself in every way. So I searched information about } \\
\text { her symptoms, mostly self-diagnosing questionnaires that you can fill out } \\
\text { online, trying to help her determine if she had mental health concerns. Now } \\
\text { she's seeing a psychiatrist." } \\
\text { "My roommate was losing a lot of hair and he's concerned. He was } \\
\text { considering using a special kind of shampoo that's supposed to stop hair loss. } \\
\text { But I thought he might want to fix this in a more natural way. So I found } \\
\text { information on hair nutrition diet for him." }\end{array}$ \\
\hline $\begin{array}{l}\text { Expansion of } \\
\text { knowledge on }\end{array}$ & $\begin{array}{l}\text { "When I read about people dying from a disease I have never heard of, I } \\
\text { would usually look it up to find out more about it." }\end{array}$ \\
\hline
\end{tabular}


interested health topics
"A few years ago I once worked on a project related aids awareness and prevention. Since then, whenever I see 'aids' appearing in news article titles, I would click into it to read more and see if there's any advancement in its treatment."

Table 2. Motivations for students' active HISB

It is worth noting that the personal injuries or medical conditions that propel students to seek information are usually of no severe consequences. Although they have the option of going to the campus clinic, most students choose not to. They seem to harbor a general distrust for the medical clinic on campus, due to either personally having negative experiences there or having learned about the clinic's unfavorable reputation from others.

\subsection{Sources of Health Information}

There are two information sources that students use when they seek health information - internet and human resources. On the internet, students rely on the following tools to search for information:

- Search engine Baidu.com - it is the dominating search engine in China and usually the first place that students visit on the internet

- Social Q\&A site Zhihu.com - it is the most popular social Q\&A site in China, where a wide variety of questions are created, answered, edited and organized by the community of its users; it is similar to Yahoo Answers (https://answers.yahoo.com/) or Quora (https://www.quora.com/) in the US.

- Social media platforms Weibo.com and Wechat.com - Weibo and Wechat are widely popular in China and they claim a monthly active users (MAU) measure of 392 million and 1,040 million respectively.

- Online services/mobile apps that enable consultation with doctors - such services (e.g. chunyuyisheng.com) connect users with certified medical professionals, allowing users to have brief consultations with doctors free of charge.

Regarding human resources, students resort to the trusted individuals in their lives for health information. Such individuals include family members and friends, and coaches on professional sports teams. It is understandable that students would consult with individuals with medical expertise - for instance, coaches are well aware of their team members' physical conditions and can offer suggestions when there are health concerns; family members and friends that are medical professionals may also provide meaningful input. Yet, some students still elect to seek out family and friends even though they do not have medical credentials, merely because they view them as trustworthy and more experienced, as shown in this quote "I ask my mom because she cares about me, and she's eaten more salt than I have eaten rice (a Chinese saying describing someone who has abundant life experience) so of course I trust her".

Two deterministic factors emerge from the focus group interviews as students discuss how they choose the information sources. First, it depends on access. If their family or friends who are medical professionals are easily reachable, they prefer consulting them first, as indicated in this quote " $m y$ parents are neighbors with several doctors, so when I'm home during winter or summer breaks, I can just ask our neighbors whenever I have a health related question". Secondly, it depends on the nature of the 
information need. When they do not want others to know about their health information inquiry, they always use the internet, as revealed in this remark "sometimes I have cold symptoms, but I think it's a sign of male weakness, so I don't tell people but quietly look up information online to find out how to get rid of it quickly."

\subsection{Evaluating Health Information}

Overall students appear to be critical about online health information. They are aware of the anonymous nature of online information. When judging the quality of the information, they tend to use the following criteria:

- Credentials of the individual or organization posting the information. Students believe that it is important to check the author credentials when examining online information. The often find the information dubious if the author appears to have a hidden agenda, as shown in this quote "Sometimes people try to get you to buy certain drugs so they exaggerate the severity of the symptoms, making you so cared". There are a lot of online posts about someone's personal experiences with a medical condition from the patient perspective, and students are cautious about them. They consider those posts to merely represent an anonymous individual's experience, which might not apply to a different person. Interestingly, if a friend or a family member shares such personal experience, they are much more likely to trust the information. Overall, they tend to deem authors with professional medical credentials (e.g. doctors, nurses) to be more credible and willing to accept the content published by them.

- Popularity or consistency of the information. Students usually lean toward information that has gained approval or recognition from most people. As shown in the comments below, students use the number of Likes/forwards, user reviews, and the number of sources providing the same information as the measures to evaluate online health information.

o "When I use Zhihu.com (a popular social Q\&A site), I always go for the post that most people Liked. I guess it's more trustworthy if a lot of people agree with it".

o "Besides looking at their credentials, I also read user reviews of the doctors that provide free consultations on mobile apps. I only choose those with positive reviews".

o "I mostly just look at websites that are on top of the search result list. If the information is consistently supported by multiple websites, l'd say it's more credible".

- $\quad$ Timeliness of the information. Students care about whether or not the information is up to date because medical and health knowledge are evolving constantly and outdated information can be misleading.

- How the information aligns with personal beliefs and experiences. When students scrutinize health information, they contextualize it with their own personal beliefs and experiences. They tend to trust the information more if it echoes their experiences or espouses their beliefs. Exemplar quotes include "If the symptoms described in the article are similar to what I'm experiencing, or the author is suggesting a remedy that I have tried successfully before, I tend to trust them" and "I believe that medicine is partially toxic. It cures one part of your body and yet damages another. So I prefer information that is more diet centric and emphasizes on natural remedies".

When discussing how to improve the quality of online health information, students provide the following ideas: 
- Health and medical information should be primarily provided by authoritative and credible health agencies (e.g. well established hospitals) and individuals (e.g. well credentialed health practitioners). People posting health information online should reveal real names so they can be held accountable for the content.

- There needs to be more information on healthy living, as well as better organized directories of doctors and hospitals.

- Develop new technologies to personalize the experience of searching health information so that the retrieved information is specific and targeted to each individual.

- Promote health literacy education among college students, raising awareness and grow their knowledge of the wide variety of health issues in order to help them become critical consumers of health information.

\subsection{Using Academic Library for Health Information}

Students rarely use the campus library to search for health information. Only one student "checked out a book on preventing sports injuries". Overall, students' conceptualization of the academic library seems to be merely a physical collection of books and study spaces. They agree that books are more trustworthy than online information, but not nearly as convenient. Three concerns are identified about using print books for health information: 1 ) books are not always up to date; 2 ) books on medical or health topics are usually too technical to understand; and 3) it is inconvenient and ineffective to search the library catalog for books or browsing books to hunt for a particular piece of information.

Despite their non-use of the academic library for health information, students admit that they would like to see the library become a place where they can easily find health information. In order for that to happen, students suggest the following improvements for libraries to consider:

- Strengthen the availability and accessibility of the electronic resources, as shown in this comment, "it is important we can access library resources from anywhere, so it's best that the library puts all the resources on the cloud, and make it compatible with mobile devices, and searchable with audio commands, etc".

- Establish a special section in the library that promotes healthy living and display the library's health information resources. It is also preferable to "set up kiosks in the section for people to browse and search the library's electronic resources".

- Change students' preconceived notions of the library - help students see the library as a reliable and convenient source for all of students' information needs, not just their needs for academic information.

\section{Discussion}

This study is the first qualitative research study examining Chinese college students' HISB and the implications for academic libraries. Findings indicate that college students are actively engaged in HISB. Their use of online and human resources for health information echoes previous studies in the literature (Sultan, Joshua \& Misra, 2017; Percheski \& Hargittai, 2011). Students are in general critical of online information and view family/friends as a more trustworthy resource. Their desire for a better online health information environment where information is published by well credentialed individuals and organizations, and health literacy education is provided for people to understand and judge the information properly. This finding has two key implications: 
- Currently, China does not have consumer-oriented health information sites that are authoritative and credible, such as MedlinePlus.gov in the United States. The landscape of online health information is filled with dubious websites and posts, and students can only resort to popularity measures (e.g. the number Likes, user reviews) for evaluation. There is an urgent need for influential health agencies (e.g. China's National Health Commission) to lead efforts in organizing and establishing the Chinese equivalent of MedlinePlus.gov and other reliable online health information resources. Libraries can become advocates in such a movement, which will not only make good use of the library profession's expertise in information organization and retrieval, but also enhance the library's image as a valuable source of information.

- It is crucial to educate college students about searching and evaluating health information and thus improve their health literacy. Previous literature has shown that college students are not proficient in seeking health information (Banas, 2008; Stellefson et al., 2011; Obasola \& Agunbiade, 2016). In this study, students also demonstrate that they can be biased by their own personal experiences or beliefs when assessing health information, raising concerns about potential pitfalls in students' health seeking journey due to such biases. Since libraries already have a well-established tradition of offering information literacy education, they may also consider incorporating health literacy in the curriculum through collaboration with health organizations on campus (e.g. academic departments related to health sciences, or Student Health and Wellness Center).

Despite academic librarians' recognition that the library should play a role in providing health information to campus constituents (Duhon \& Jameson, 2013), this study finds that students rarely consider the campus library as a source of health information. The barriers identified in this study include Chinese students' perception of the library as merely a physical space and a physical collection of materials, inconvenience of searching for books and inadequate consumer-oriented and timely books on medical and health topics. Still students agree that, if the barriers can be overcome, they would definitely use the library for health information as the library is a representation of authoritativeness and trustworthiness. This finding is encouraging in that students welcome the library to be more actively involved in their health information seeking process. Here are some suggestions for academic libraries to consider:

- Outreach. Active outreach is essential to helping students view the library beyond the limits of a physical entity. Programs raising student's health awareness can be good opportunities to introduce the library's electronic resources that students can access anytime and anywhere. For instance, during the stressful period of finals, the library may organize a "Distress and Destroy" event where students can come to a designated space in the library and crush empty cardboard boxes during their study breaks. On one hand, such an event can help students alleviate stress; on the other hand, the library can use the event as a platform to connect students with library resources (particularly e-resources) on stress management and how to get help if they need psychiatric consultation. Considering academic libraries as merely a place to study and check out books is not uncommon among Chinese students. Such a viewpoint still may exist among international students from China as they study in western countries where the concept and practices of libraries is more dynamic. Thus, it would also be beneficial for academic librarians in the west to be mindful about this stereotypical view as they provide services to Chinese international students. 
- Community collaboration. Collaborating with community partners is indispensable as libraries endeavor to help students seek health information. Health-related academic units on campus, and local health clinics and non-profit health organizations, can be effective partners as the library develops health focused resources and programs for students. For instance, on the World Health Day, the library may work with the campus and local health community to organize a health fair, where relevant library resources and services can be highlighted and promoted among students.

- Health information resources. In addition to the library's own collections and resources on health and medical topics, academic libraries may consider developing resource guides that also include credible resources freely available on the internet, and joining library consortia that would allow students to check out materials from more specialized consumer health libraries.

- Instruction. Providing instructions on health information seeking is pivotal to the enhancement of students' health literacy. Librarians may develop self-paced tutorials or offer in person workshops on health information resources, search strategies, and evaluation criteria. Again, community partners can be a valuable resource in offering health literacy instruction.

Overall, this study suggests that there is great potential for academic libraries to be involved and supportive in students' health information seeking process. As college students' health literacy improves, tragedies such as what happened to Zexi Wei, will eventually diminish.

\section{Conclusion}

This study provides an in-depth depiction of college students' HISB, offering a fresh perspective in this predominantly quantitative field and adding a more nuanced understanding on this topic. It is the first study that qualitatively examines the HISB among Chinese students, a population that has not been well studied. Furthermore, it explores the academic library's role in students' health information seeking process, answering Duhon and Jameson's (2013) call to enrich research and practice in this area. Some of the research findings may constitute the building blocks for future research on HISB in the context of college campuses and academic libraries. For instance, the findings about students' health information evaluation criteria, may help refine the scale on students' trust judgements in online health information seeking developed by Rowley, Johnson and Sbaffi (2015) and lead to more relevant research.

Yet it is necessary to recognize the study's limitations - the generalizability of the findings is limited due to the small sample size of the study, and patterns of students' health information seeking are drawn from self-reports instead of direct observations, and thus may contain the inherent biases of selfreported data. Future research may build upon this study to investigate this topic at a larger scale and employ a wide range of methods to further examine how students search and evaluate health information and how libraries can play a positive role in this process.

\section{References}

American Institute for Research. (2006). New study of the literacy of college students finds some are graduating with only basic skills. Retrieved from https://www.air.org/news/press-release/newstudy-literacy-college-students-finds-some-are-graduating-only-basic-skills 
Asibey, B., Agyemang, S. \& Dankwah, A. (2017). The internet use for health information seeking among Ghanaian university students: A cross-sectional study. International Journal of Telemedicine and Applications, 2017, 1-9.

Babbie, E. (2013). The practice of social research. Belmont, CA: Wadsworth Cengage Learning.

Banas, J. (2008). A tailored approach to identifying and addressing college students' online health information literacy. American Journal of Health Education, 39(4), 228-236.

Barr-Walker, J. (2016). Health literacy and libraries: A literature review. Reference Services Review, 44(2), 191-205.

Calder, B. J. (1977). Focus groups and the nature of qualitative marketing research. Journal of Marketing Research, 13, 353-364.

Duhon, L. \& Jameson, J. (2013). Health information outreach: A survey of U.S. academic libraries, highlighting a Midwestern university's experience. Health Information and Libraries Journal, 30, 121-137

Ickes, M. \& Cottrell, R. (2010). Health literacy in college students. Journal of American College Health, $58(5), 491-498$.

Institute of Medicine. (2004). Health literacy: A prescription to end confusion. Retrieved from http://www.nationalacademies.org/hmd/Reports/2004/Health-Literacy-A-Prescription-to-EndConfusion.aspx

Islam, M., Touray, M., Yang, H., Poly, T., Nguyen, P., Li, Y. \& Abdul, S. (2017). E-health literacy and health information seeking behavior among university students in Bangladesh. Studies in Health Technology Informatics, 245,122-125.

Ivanitskaya, L., Boyle, I. \& Casey, A. (2006). Health information literacy and competencies of information age students: Results from the interactive online research readiness self-assessment (RRSA). Journal of Medical Internet Research, 8(2), 1-13.

Kars, M., Baker, L. M. \& Wilson, F. L. (2008). The Medical Library Association guide to health literacy. New York: Neal-Schuman Publishers.

Mahmood, K. (2016). Do people overestimate their information literacy skills? A systematic review of empirical evidence on the Dunning Kruger effect. Communications in Information Literacy, 10(2), 198-213.

Merton, R. K. (1987). Focused interviews and focus groups: Continuities and discontinuities. Public Opinion Quarterly, 51, 550-566.

Ministry of Public Health of China. (2017). 2016 Chinese citizens' health literacy monitoring report (in Chinese). Retrieved from http://www.gov.cn/shuju/2017-11/22/content 5241572.htm

Obasola, O. \& Agunbiade, O. (2016). Online health information seeking pattern among undergraduates in a Nigerian university. SAGE Open, 6(1), 1-9. 
Percheski, C. \& Hargittai, E. (2011). Health information seeking in the digital age. Journal of American College Health, 59(5), 379-386.

Rowley, J. Johnson, F. \& Sbaffi, L. (2015). Students' trust judgements in online health information seeking. Health Informatics Journal, 21(4), 316-327.

Stellefson, M., Hanik, B., Chaney, B., Chaney, D., Tennant, B. \& Chavarria, E. (2011). eHealth literacy among college students: A systematic review with implications for eHealth education. Journal of Medical Internet Research, 13(4), 1-11.

Stewart, D., Shamdasani, P., \& Rook, D. (2007). Focus groups: Theory and practice. Thousand Oaks, CA: Sage.

Sultan, K., Joshua, V. \& Misra, U. (2017). Health information seeking behavior of college students in the Sultanate of Oman. Khyber Medical University Journal, 9(1), 8-14.

US Department of Health and Human Services. 2000. Quick guide to health literacy. Retrieved from https://health.gov/communication/literacy/quickguide/factsbasic.htm

Vogelpohl, M. \& Carpenter, D. (2013). Improving the health literacy of a university: A collaborative campus effort. Paper presented at American College Health Association 2013 Annual Meeting, Boston, MA. 